\title{
Integrated measurements of acoustical and optical thin layers I: Vertical scales of association
}

\author{
Kelly J. Benoit-Bird ${ }^{\mathrm{a}, *}$, Mark A. Moline ${ }^{\mathrm{b}}$, Chad M. Waluk ${ }^{\mathrm{a}}$, Ian C. Robbins ${ }^{\mathrm{b}}$ \\ ${ }^{a}$ College of Oceanic and Atmospheric Sciences, Oregon State University, 104 COAS Administration Building, Corvallis, OA 97331, USA \\ b Biological Sciences Department, Center for Marine and Coastal Sciences, California Polytechnic State University, San Luis Obispo, CA 93407, USA
}

\begin{abstract}
A B S T R A C T
This study combined measurements from multiple platforms with acoustic instruments on moorings and on a ship and optics on a profiler and an autonomous underwater vehicle (AUV) to examine the relationships between fluorescent, bioluminescent, and acoustically scattering layers in Monterey Bay during nighttime hours in July and August of 2006 and May of 2008. We identified thin bioluminescent layers that were strongly correlated with acoustic scattering at the same depth but were part of vertically broad acoustic features, suggesting layers of unique composition inside larger biomass features. These compositional thin layers nested inside larger biomass features may be a common ecosystem component and are likely to have significant ecological impacts but are extremely difficult to identify as most approaches capable of the vertical scales of measurement necessary for the identification of sub-meter scale patterns assess bulk properties rather than specific layer composition. Measurements of multiple types of thin layers showed that the depth offset between thin phytoplankton and zooplankton layers was highly variable with some layers found at the same depth but others found up to $16 \mathrm{~m}$ apart. The vertical offset between phytoplankton and zooplankton thin layers was strongly predicted by the fraction of the water column fluorescence contained within a thin phytoplankton layer. Thin zooplankton layers were only vertically associated with thin phytoplankton layers when the phytoplankton in a layer accounted for more than about $18-20 \%$ of the water column chlorophyll. Trophic interactions were likely occurring between phytoplankton and zooplankton thin layers but phytoplankton thin layers were exploited by zooplankton only when they represented a large fraction of the available phytoplankton, suggesting zooplankton have some knowledge of the available food over the entire water column. The horizontal extent of phytoplankton layers, discussed in the second paper in this series, is likely an important factor contributing to this selective exploitation by zooplankton. The pattern of vertical offset between phytoplankton and zooplankton layers was consistent between studies in different years and using different combinations of platforms, indicating the importance of the relationship between zooplankton layers and the fraction of phytoplankton within a layer at night within Monterey Bay. These results highlight the value of integrating measurements of various types of organisms to understand thin layers processes and the importance of assessing ecological interactions in plankton thin layers within the context of the properties of the entire water column, like the animals themselves do.
\end{abstract}

\section{Introduction}

Over the last two decades, dense layers of plankton with vertical dimensions of tens of centimeters have been described from a variety of coastal marine habitats (e.g. Cheriton et al., 2007; Donaghay et al., 1992; Holliday et al., 2003; Osborn, 1998). These 'thin layers' can have a horizontal extent of several kilometers and may persist for days or even weeks (Dekshenieks et al., 2001; McManus et al., 2003; Rines et al., 2002). Sharply distinct from the surrounding water column, the density of phytoplankton and zooplankton in these layers can be orders of magnitude higher than at surrounding depths (Cowles, 2003). This intense concentration of acoustically and optically significant plankton biomass as well as the ubiquity of these features in coastal ecosystems (Cheriton et al., 2007) has important implications for both our sampling approach and ecological interactions in these systems.

Despite the indications that plankton thin layers could have significant ecosystem effects, studies of these impacts have been limited. Using ship-board grazing experiments, Lasker (1975) 
showed that the abundance of appropriate food in intense phytoplankton layers rather than the average abundance of food in the water column is critical for the survival of larval fish. More recent laboratory (Clay et al., 2004; Ignoffo et al., 2005; MendenDeuer and Grunbaum, 2006) and modeling (Leising, 2001) studies confirm that thin layers play a significant role in trophic interactions and thus the behavior, growth, and reproduction of individual organisms and ultimately the flux of carbon and nutrients in ecosystems. Field studies investigating the ecological consequences of thin plankton layers, however, have been limited at least in part because of the difficulties in studying the biological processed involved in the formation and persistence of thin layers.

A decade ago, Cowles et al. (1998) highlighted a gap in our understanding of thin layers, noting that few papers before that time presented measurements of small-scale biology with concurrent measurements of physical variables on the appropriate time and space scales. In the time since that publication, substantial progress has been made in our understanding of the physical processes controlling the formation and maintenance of thin layers. See, for example Birch et al., 2008; Ryan et al., 2008; McManus et al., 2003; Osborn 1998, and several of the companion papers in this issue. Studies linking observations of physics and biology have also supported active swimming as an important mechanism controlling thin layers of both zooplankton (Gallager et al., 2004; McManus et al., 2005) and motile phytoplankton (Klausmeier and Litchman, 2001). A recent model by Stacey et al. (2007) quantifies the relative importance of motility, straining, and buoyancy, integrating this biological process with physical processes. A variety of other biological mechanisms for thin layer formation and maintenance have been proposed including thinning by preferential grazing at the edges of existing layers, increased reproduction, and increased growth within layers (Donaghay and Osborn, 1997). These biological mechanisms have substantial implications for the ecological role of thin layers though they remain largely untested in field experiments. We argue that in order to make advances in our understanding of these biological processes and their ecological consequences that are comparable to those recently achieved for physical forcing requires concurrent, appropriately scaled measurements of multiple trophic levels. Most previous field studies of thin layers have focused specifically on phytoplankton (e.g., Cowles et al., 1998;
Dekshenieks et al., 2001; McManus et al., 2007; Osborn, 1998; Rines et al., 2002; Ryan et al., 2008; Sullivan et al., 2005) and to a lesser extent, zooplankton (Cheriton et al., 2007; Holliday et al., 2003; Holliday et al., 1998; McManus et al., 2005; Widder et al., 1999), with only a few studies attempting to integrate measures of multiple trophic levels (Donaghay et al., 1992; Gallager et al., 2004; McManus et al., 2003).

Integrated studies of thin layers at multiple trophic levels have been limited by the difficulties in making measurements of multiple sizes of organisms in meter-scale thick aggregations simultaneously at similar scales, the often disparate techniques (and thus investigators) needed for different organisms, and the challenges in quantitatively assessing layer associations. The multi-investigator, interdisciplinary research initiative termed Layered Organization in the Coastal Ocean (LOCO) supported by the US Office of Naval Research presented an opportunity to overcome some of these challenges. The goal of this work, a component of the LOCO program, was to examine the relationships between fluorescent, bioluminescent, and acoustically scattering layers in Monterey Bay in an effort to understand the interactions between adjacent trophic levels, assess the influence of bioluminescence on these interactions, and to elucidate potential mechanisms involved in the differential formation of these layers. We addressed these questions by combining measurements from multiple platforms with acoustic instruments on moorings and on a ship and optics on a profiler and an autonomous underwater vehicle (AUV). The combination of data between these various platforms was designed to elucidate the multi-dimensional overlap of trophic levels found in and around thin layers.

\section{Methods}

Sampling was conducted from four platforms in various combinations over 11 nights in July and August 2006 and May 2008 bringing together measurements of physical, optical, and acoustical properties of the water column in the Northeast corner of Monterey Bay, California, USA in an area roughly bounded by $36.955^{\circ} \mathrm{N} 121.954^{\circ} \mathrm{W}, 36.933^{\circ} \mathrm{N} 121.896^{\circ} \mathrm{W}, 36.906^{\circ} \mathrm{N} 121.912^{\circ}$ $\mathrm{W}, 36.920^{\circ} \mathrm{N}, 121.958^{\circ} \mathrm{W}$ (Fig. 1).

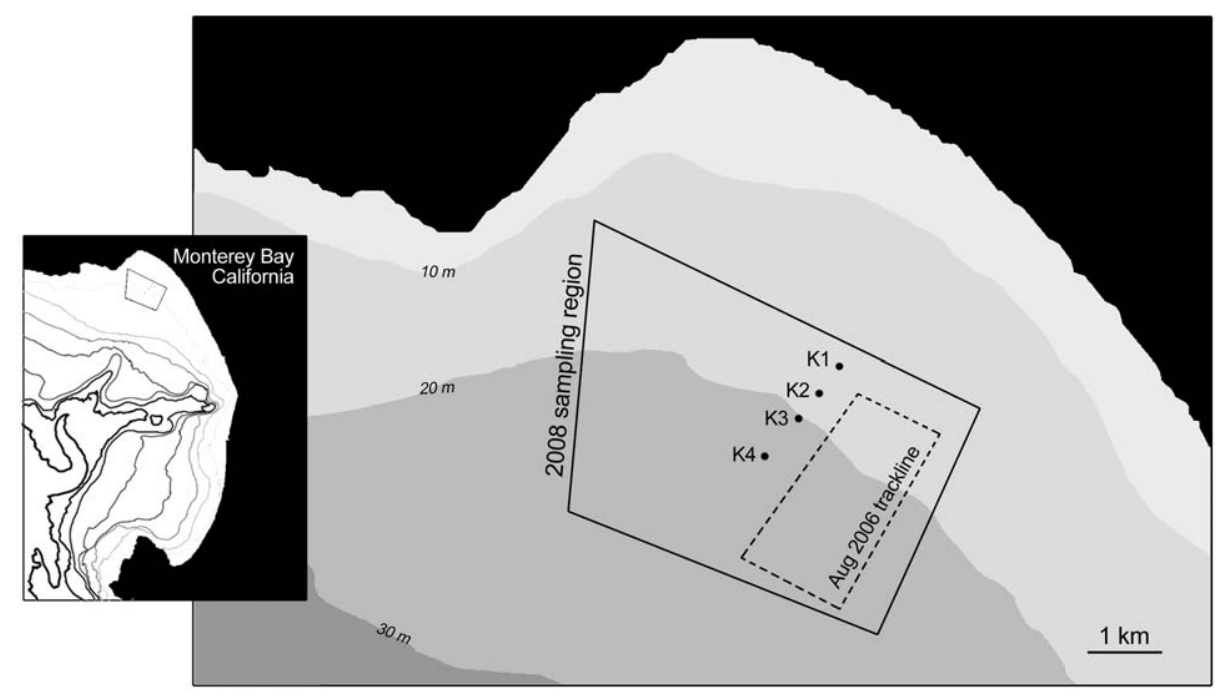

Fig. 1. A map of the study region in the northeast corner of Monterey Bay. In the map of the entire bay on the left, the $50,100,200,500,1000,2000$, and $5000 \mathrm{~m}$ isobaths are

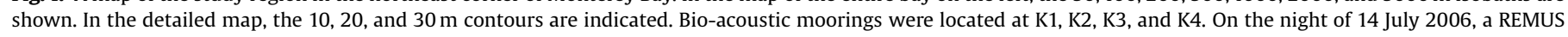

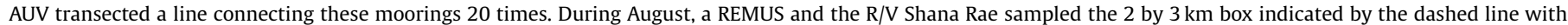
CTD profiles at each corner. During 2008, all sampling was carried out from the R/V Shana Rae within the region bounded by the solid line. 


\subsection{July 2006}

From $2100 \mathrm{~h}$ local time on the night of 14 July until $0215 \mathrm{~h}$ local time the morning of 15 July, two 1.8 m REMUS AUVs (Moline et al. 2005), equipped with a variety of optical and physical sensors, repeatedly transected a line running offshore from the main LOCO site, covering this area 20 times over the course of the night (Fig. 1). Four bio-acoustic moorings were deployed along this line sampled acoustic scattering from zooplankton once every $4 \mathrm{~s}$. This merger of moored and AUV data provides insight into both spatial and short term temporal variation in thin layers of phytoplankton and zooplankton.

\subsubsection{Autonomous underwater vehicle}

In conjunction with the bio-acoustic moorings, two REMUS AUVs were used to undulate a line over the mooring sites. The vehicles were programmed to undulate between $2 \mathrm{~m}$ depth and $3 \mathrm{~m}$ altitude above a variable bottom depth at a speed of approximately $2 \mathrm{~m} / \mathrm{s}$. Navigation of the AUV was by acoustic triangulation using an array of digital acoustic transponders deployed in the area of study for the duration of a mission. Error in horizontal position from navigation approach is largely based on GPS errors for the transponders. Here, the horizontal position uncertainty for the vehicles is estimated at $<5 \mathrm{~m}$ (Hibler et al. 2008). The two vehicles provided measures of chlorophyll fluorescence (Wetlabs Inc. ECO-triplet) and salinity and temperature using an Ocean Sensors OS-200 CTD. A bioluminescence bathyphotometer was also to quantify the bioluminescence potential of the water. The bathyphotometer is described in Herren et al. (2005) but briefly, a centrifugal-type impeller pump drives water into an enclosed $500 \mathrm{ml}$ chamber and creates turbulent flow, which mechanically stimulates bioluminescence. The measurement from the bathyphotomer is therefore an index of the total luminescent capacity of organisms in a set water volume. A flowmeter monitors pumping rates using a magnet and a Hall-effect sensor to generate a period signal, which is converted to an analog signal of flow rate. The flow rates are measured as the water passes from the detection chamber to exhaust outlets. In order to prevent premature stimulation of bioluminescence by the moving vehicle, water is taken directly through the front nose section of the vehicle. Two light baffling turns in the nose serve to minimize ambient light contamination. No significant ram-effect on light production or flow rate from the vehicle itself has been found with this integrated system (Blackwell et al., 2002). Sampling with the REMUS outfitted with the bathyphotometer was conducted between 2200 and 0400 local time as bioluminescence is a diurnally dependant measure, but it has been shown to be generally stable during this $6 \mathrm{~h}$ period at this latitude at this time of the year (Moline et al., 2001).

\subsubsection{Moored acoustics}

Four, upward-looking $200 \mathrm{kHz}$ self-contained bio-acoustic sensors (water column profiler WCP, ASL Environmental Sciences), were deployed approximately $500 \mathrm{~m}$ apart, in a line running roughly offshore from the $15 \mathrm{~m}$ isobath in the northeast corner of Monterey Bay (Fig. 1). Each WCP was attached directly to sandbag anchors so that the transducer was approximately $1 \mathrm{~m}$ off the seafloor with substantial floatation under the transducer for stability. This stability was confirmed using readings from a logging tilt and roll sensor in each instrument. No floats or lines were deployed above the instrument package to limit unintended acoustic returns and the aggregation of animals which is sometimes observed around surface floats. Recovery of each WCP was accomplished using acoustic releases that permitted the instrument package to float to the surface, sacrificing the sandbag anchors. The WCPs used a pulse length of $156 \mu$ s and had a $3 \mathrm{~dB}$ beamwidth of $10^{\circ}$. Each was calibrated in a seawater tank using procedures similar to those used for the ship-board echosounders. Each of the WCPs collected volume backscatter data from 12 July to 29 July at a rate of $0.25 \mathrm{~Hz}$ with a vertical resolution of $12.45 \mathrm{~cm}$. For the purposes of this paper, only data collected on the night of 14 July into the early morning of 15 July when the REMUS made repeated flights over the line of moorings was examined.

\subsection{August 2006}

From 4 August to 8 August 2006, immediately following the main LOCO experiment, nighttime sampling was conducted from two platforms. The REMUS AUV, equipped and deployed in a manner identical to that described in Section 2.1.2, undulated along the edges of $3 \mathrm{~km}$ across isobath by $2 \mathrm{~km}$ along isobath box (Fig. 1) as many times as was feasible within a single night. The sampling box was also sampled using multi-frequency acoustics from the $16 \mathrm{~m} \mathrm{R} / \mathrm{V}$ Shana Rae. Underway surveying from the R/V Shana Rae was conducted at a vessel speed of approximately $9.26 \mathrm{~km} / \mathrm{h}$ (5 knots) with the transducers of a 38 and $120 \mathrm{kHz}$ split-beam echosounder (Simrad EK60 s) mounted $1 \mathrm{~m}$ beneath the surface on a rigid pole off the side of the vessel. The $120 \mathrm{kHz}$ echosounder had a $7^{\circ}$ beam and used a $64 \mu$ s pulse providing a vertical resolution of $2.5 \mathrm{~cm}$. The $38 \mathrm{kHz}$ echosounder had a $12^{\circ}$ beam and used a $256 \mu$ s long pulse providing a vertical resolution of $10 \mathrm{~cm}$. Both echosounders were calibrated in the field using an indirect procedure incorporating a $38.1 \mathrm{~mm}$ diameter tungsten carbide reference sphere as prescribed by Foote et al. (1987) using the same set up used for the study. For calibration, the reference sphere was held between 10 and $12 \mathrm{~m}$ away from the transducers to ensure measurement in the far field.

In addition to underway acoustic sampling from the vessel, CTD casts to within $3 \mathrm{~m}$ of the seafloor were conducted each time a corner of the sampling box was passed using an SBE25 equipped with a WetLabs WetStar Fluorometer. The CTD data provided a cross check of the sampling from the two platforms. Vertical net tows were periodically conducted with a 0.75 diameter, $333 \mu \mathrm{m}$ mesh net equipped with a General Oceanics flowmeter to allow calculation of volume sampled. The net was lowered until a weight $3 \mathrm{~m}$ from the ring reached the seafloor and then pulled to the surface at a rate of approximately $1 \mathrm{~m} / \mathrm{s}$. Samples were preserved in $5 \%$ buffered formalin in seawater for later analysis.

\subsection{May 2008}

From 19 May to 28 May 2008, nighttime sampling from all instruments was conducted from the R/V Shana Rae. Sampling included station keeping to obtain time-series data and transects with both underway sampling and closely spaced vertical profiles with the CTD package. During station keeping, ship-board acoustic sampling was carried out continuously with a series of three contiguous CTD casts every $30 \mathrm{~min}$ and a single, vertically integrated net tow once each hour. The $3 \mathrm{~km}$ long transects were sampled at an underway speed of $9.26 \mathrm{~km} / \mathrm{h}$ repeatedly over the course of a single night with a series of three, contiguous CTD casts at least every $500 \mathrm{~m}$ along the transect and intermittent vertical net tows.

Similar to 2006, the transducers of $38,70,120$, and $200 \mathrm{kHz}$ split-beam echosounders (Simrad EK60s) were mounted $1 \mathrm{~m}$ beneath the surface on a rigid pole off the side of the vessel. The $38 \mathrm{kHz}$ echosounder had a $12^{\circ}$ conical beam. The $70 \mathrm{kHz}$ echosounder had a $7^{\circ}$ conical beam. The 120 and $200 \mathrm{kHz}$ echosounders each had a $7^{\circ}$ conical beam. All four frequencies used a $256 \mu$ s pulse resulting in a vertical resolution of $10 \mathrm{~cm}$. The 
echosounders were calibrated in the field following the same methods as the 2006 sampling.

Bioluminescence, fluorescence, optical backscatter, and acoustic backscatter at 6 frequencies were all measured from the same profiling package. The package consisted of an SBE19plus CTD with an SBE 43 dissolved oxygen senor, and several optical instruments from WetLabs: an ECO-flntu fluorometer, C-Star transmissometer ( $25 \mathrm{~cm}$ pathlength, $530 \mathrm{~nm}$ wavelength), and a Wetlabs Inc. UBAT bioluminescence sensor. The UBAT sensor is similar to bathyphotometer integrated in the REMUS with a slightly smaller detection chamber $(400 \mathrm{ml})$ and a faster sampling rate. Cross-calibration between the UBAT and REMUS instruments was ensured using a standard isotropic light source probe inserted into the individual stimulation chambers (Herren et al., 2005).

Vertical net tows were conducted with a 0.75 diameter, $333 \mu \mathrm{m}$ mesh net equipped with a General Oceanics flowmeter to allow calculation of volume sampled. The net was lowered until a weight $3 \mathrm{~m}$ from the ring reached the seafloor and then pulled to the surface at a rate of approximately $1 \mathrm{~m} / \mathrm{s}$. Samples were preserved in $5 \%$ buffered formalin in seawater for later analysis. In the laboratory, samples were identified to species, enumerated, and measured.

\subsection{Data analysis}

Calibrations were applied to data from the upward looking $200 \mathrm{kHz}$ echosounders in Matlab and then the volume scattering data were imported into Myriax's Echoview software for further analysis. Data were kept at their full resolution vertically but averaged over 10 pings and thresholded at $-80 \mathrm{~dB}$ before analysis for thin layers.

Echosounder data from the 38 and $120 \mathrm{kHz}$ (2006 and 2008) and $200 \mathrm{kHz}$ (2008 only) echosounders were analyzed in Myriax's Echoview software. Data were averaged over 10 pings and thresholded at $-80 \mathrm{~dB}$ before analysis for thin layers. The difference in volume scattering between the 120 and $38 \mathrm{kHz}$ echosounders of identified layers was calculated because a mean volume backscatter difference of less than $3 \mathrm{~dB}$ indicates that scattering could have been caused by fish while layers with a strong frequency response are highly likely to have been caused by zooplankton (Kang et al., 2002; Korneliussen, 2000). No layers were identified as echoes consistent with fish, however. For all acoustic analyses, a constant sound speed was used to calculate target range. Based on the range of sound speed values measured, this could introduce a maximum of $\pm 5 \mathrm{~cm}$ of error into the vertical position of scattering features.

Data from CTD casts were low passed filtered and edited for loops before the raw variables were converted to variables of interest using factory calibrations. Fluorometer calibration equations were confirmed from periodic samples of water filtered for chlorophyll in the area of the experiment. Before analysis for thin layers was conducted on each downcast, all optical data were filtered with a 5-point Gaussian window filter to smooth spikes that can affect the detection of layer edges.

Data from the REMUS were edited for loops before the raw variables were converted to variables of interest. Before analysis for thin layers, any ascents or descents that did not cover at least $70 \%$ of the intended dive depth were discarded.

From both the REMUS and CTD profiler's bathyphotometer, the variance and mean bioluminescence potential over the depth each identified thin bioluminescent layer were calculated. The ratio of the square root of variance to the mean bioluminescence potential, or coefficient of variation, has been shown to be a good index of the identity of the bioluminescent organisms in Monterey Bay (Moline et al., 2008). Values of this ratio that are less than 0.5 indicate the frequent but less bright flashes of dinoflagellates, while values higher than this indicate the bright but infrequent flashes of zooplankton.

\subsubsection{Defining thin layers}

In all data from all platforms, thin layers were defined in the same way. A running, $5 \mathrm{~m}$ vertical median was taken for each profile of the REMUS, 10-ping average from the echosounders, or CTD cast. In each case, the points at which the layer crossed above the running median were used to define the upper and lower edges of the layer. The average value of these two crossing points was used to define the local background value. The depth of the layer was defined as the point at which the layer reached a maximum value. The thickness of the layer was calculated as the range of values within half the peak intensity of the layer, sometimes called the full width half maximum (FWHM). Features were defined as thin layers when their peaks exceeded 1.2 times the local background with a FWHM thickness less than $3 \mathrm{~m}$. In addition, acoustically identified layers must have persisted for at least 20 s. For REMUS and CTD data, layers must have been present in at least two profiles in the same area within $1 \mathrm{~h}$ or in profiles at adjacent locations.

\subsubsection{Data integration}

In the 15 July 2006 data, only segments of the REMUS track within $100 \mathrm{~m}$ of each mooring were analyzed. Horizontal position was ignored from these segments to create vertical profiles that were compared to 10-ping averaged vertical profiles of acoustic data from the adjacent mooring at the same time.

During the August 2006 study, data were taken from two mobile platforms that were coordinated in their movement. Because the average REMUS profile covered $125 \mathrm{~m}$ horizontally, 10-ping averaged ship-board echosounder data were analyzed for the presence of zooplankton thin layers every $125 \mathrm{~m}$ to provide roughly comparable sample sizes between the two platforms. Direct comparisons between optical and acoustical thin layers were limited to segments of transects that occurred in the same location on both platforms within 20 min of each other.

For the May 2008 data, the 10-ping averaged echosounder data from just before each CTD cast were analyzed along with the data from the cast. The acoustic data from just prior to the cast were used in case the lowering of the CTD caused any change in the behavior of zooplankton. The depths of the peaks of acoustically and optically identified thin layers were compared.

In 2006, acoustic scattering layers were detected from moorings which used a $200 \mathrm{kHz}$ signal and ship-board acoustics which used a $120 \mathrm{kHz}$ signal. It is possible that this difference in frequency could cause differences in detection of layers or their characteristics. In 2008, both 120 and $200 \mathrm{kHz}$ were used simultaneously from the same platform. Layers were independently detected in each frequency and their detections and layer characteristics compared with paired $t$-tests.

Bioluminescence is produced by over 700 genera representing 16 phyla spanning the range of small, single-cell bacteria to large vertebrates. Previous work in Monterey Bay has suggested that the primary sources of bioluminescence are dinoflagellate phytoplankton and various species of copepod zooplankton (Moline et al., 2008). During all three studies, the peak depths of thin layers of bioluminescence were compared with the depths of fluorescent and acoustically scattering thin layers as well as integrated values of these variables over the depth of the bioluminescent layer to separate the potential sources of bioluminescence. 


\section{Results}

\subsection{Confirmation of methodologies}

\subsubsection{Net tows}

Net sampling focused directly on thin layers was not possible during this study, however, water column integrated zooplankton tows showed that in both years, zooplankton captured in the net were dominated by copepods numerically and by biomass. In all three study periods, the most abundant genera of copepods was Calanus (mean body length $1.35 \mathrm{~mm}$, standard deviation $=0.29$ ), Ctenocalanus (mean length $0.90 \mathrm{~mm}$, standard deviation $=0.06$ ), and Acartia (mean length $0.95 \mathrm{~mm}$, standard deviation $=0.08$ ). Together, these three groups made up more than $90 \%$ of the zooplankton both numerically and by biomass. The relatively limited diversity of body types and the lack of any extremely strong scatterers such as gastropods or those with air inclusions suggests that scattering can reasonably used as an estimate of relative abundance of zooplankton over depth. The consistent species and size distribution between studies allows for comparisons of these relative abundance measures to be made across studies. While avoidance if the net by larger zooplankton is likely, this avoidance would likely be similar across studies and thus not likely to bias the inter-study comparisons.

\subsubsection{Frequency effects on acoustic scattering layer detection}

In 2006, acoustic scattering layers were detected from moorings which used a $200 \mathrm{kHz}$ signal and ship-board acoustics which used a $120 \mathrm{kHz}$ signal. It is possible that this difference in frequency could cause differences in detection of layers or their characteristics. In 2008, both 120 and $200 \mathrm{kHz}$ echosounders were used simultaneously from the same platform. All identified zooplankton layers were detected at both 120 and $200 \mathrm{kHz}$. Paired $t$-tests showed no significant differences ( $p>0.05$ for all comparisons) in the thickness, peak values, peak value relative to local background, or layer percent of total water column scattering suggesting that thin layer results are comparable at these two frequencies.

\subsubsection{Fluorescence and optical scattering}

During the 15 July 2006 study, the peak depth of optical backscattering layers and fluorescent layers were significantly correlated with $(R=0.96, p<0.001, \mathrm{df}=66)$. The slope of this relationship was not significantly different from $1(p>0.05)$ and the $y$-intercept was nearly zero. The ratio of the peak value to the local background of fluorescent and optically scattering layers were also significantly correlated $(R=0.83, p<0.01, \mathrm{df}=66)$. The slope of this relationship was not significantly different from 1 $(p>0.05)$ and the $y$-intercept was close to zero. Similarly, the peak depths of fluorescent and optically scattering layers in the August 2006 were strongly correlated $(R=0.94, p<0.001, \mathrm{df}=66$, slope not significantly different from $1, y$-intercept not significantly different from 0 ). This suggests that there is no residual chlorophyll quenching affecting our ability to resolve thin layers of fluorescence as expected during nighttime sampling. The results also suggest that the dominant optical backscattering particles were chlorophyll containing. Because of the ubiquity of fluorescence measurements across the experiments, phytoplankton layers will be primarily described by fluorescence in the remainder of the results.

\subsection{Plankton thin layers}

A summary of nighttime layer occurrence with the characteristics of detected layers from all three studies is shown in Table 1. In all studies, layers were relatively common during the nighttime

Table 1

Summary of thin layer characteristics from each of the 3 study periods.

\begin{tabular}{|c|c|c|c|c|c|c|c|c|c|c|c|c|c|}
\hline & \multirow[t]{2}{*}{ Platform } & \multicolumn{2}{|c|}{ Occurrence } & \multicolumn{2}{|c|}{$\begin{array}{l}\text { Layer peak } \\
\text { depth }\end{array}$} & \multicolumn{2}{|c|}{ Peak value } & \multicolumn{2}{|c|}{ Peak/background } & \multicolumn{2}{|c|}{ Thickness } & \multicolumn{2}{|c|}{ Layer/total } \\
\hline & & $\begin{array}{l}\mathrm{N} \\
\text { layers }\end{array}$ & $\begin{array}{l}\text { Percentage } \\
\text { of profiles } \\
(\%)\end{array}$ & Mean & SD & Mean & SD & Mean & SD & Mean & SD & Mean & SD \\
\hline \multicolumn{14}{|l|}{15 July 2006} \\
\hline $\begin{array}{l}\text { Fluorescence (chl } \\
\text { mg/L) }\end{array}$ & REMUS & 74 & 36 & 13.59 & 1.83 & 16.73 & 3.00 & 1.44 & 0.22 & 0.31 & 0.22 & 0.08 & 0.06 \\
\hline $\begin{array}{l}\text { Optical backscatter } \\
\text { (relative units) }\end{array}$ & REMUS & 116 & 56 & 14.07 & 1.98 & 0.02 & 0.00 & 1.57 & 0.24 & 0.37 & 0.24 & 0.16 & 0.06 \\
\hline $\begin{array}{l}\text { Bioluminescence } \\
\text { (photons/L/s) }\end{array}$ & REMUS & 90 & 43 & 11.91 & 3.54 & $2.47 \mathrm{E}+11$ & $5.46 \mathrm{E}+10$ & 3.13 & 3.51 & 0.75 & 0.68 & 0.24 & 0.15 \\
\hline $\begin{array}{l}\text { Acoustical } \\
\text { backscatter (dB) }\end{array}$ & $\begin{array}{l}4 \\
\text { Moorings }\end{array}$ & 91 & 37 & 7.28 & 2.85 & -41.42 & -48.24 & 3.80 & 3.63 & 1.54 & 0.84 & 0.31 & 0.51 \\
\hline \multicolumn{14}{|l|}{ August 2006} \\
\hline $\begin{array}{l}\text { Fluorescence (chl } \\
\text { mg/L) }\end{array}$ & REMUS & 395 & 76 & 9.72 & 2.58 & 12.56 & 2.83 & 1.70 & 0.42 & 0.69 & 0.36 & 0.32 & 0.09 \\
\hline $\begin{array}{l}\text { Optical backscatter } \\
\text { (relative units) }\end{array}$ & REMUS & 284 & 55 & 9.83 & 2.69 & 0.02 & 0.00 & 1.40 & 0.19 & 0.50 & 0.58 & 0.18 & 0.08 \\
\hline $\begin{array}{l}\text { Bioluminescence } \\
\text { (photons/s) }\end{array}$ & REMUS & 194 & 37 & 13.88 & 3.32 & $1.84 \mathrm{E}+11$ & $4.30 \mathrm{E}+10$ & 2.08 & 1.64 & 0.76 & 0.51 & 0.31 & 0.13 \\
\hline $\begin{array}{l}\text { Acoustical } \\
\text { backscatter (dB) }\end{array}$ & Ship & 260 & 42 & 12.43 & 6.36 & -36.40 & -30.80 & 6.30 & 8.07 & 1.37 & 0.70 & 0.29 & 0.36 \\
\hline \multicolumn{14}{|l|}{ May 2008} \\
\hline $\begin{array}{l}\text { Fluorescence (chl } \\
\text { mg/L) }\end{array}$ & CTD & 56 & 33 & 7.17 & 3.94 & 16.19 & 3.99 & 1.38 & 0.16 & 0.34 & 0.35 & 0.16 & 0.09 \\
\hline $\begin{array}{l}\text { Bioluminescence } \\
\text { (photons/L/s) }\end{array}$ & CTD & 87 & 59 & 10.27 & 3.73 & $5 . E+10$ & $3 . E+10$ & 3.17 & 1.94 & 0.38 & 0.71 & 0.28 & 0.13 \\
\hline $\begin{array}{l}\text { Acoustical } \\
\text { backscatter (dB) }\end{array}$ & Ship & 50 & 30 & 10.60 & 5.12 & -58.14 & -53.47 & 4.41 & 4.81 & 0.96 & 0.62 & 0.28 & 0.29 \\
\hline
\end{tabular}

Note that while the peak of acoustical scattering is reported in $\mathrm{dB}$, all statistical calculations were carried out on a linear form of acoustic scattering. 

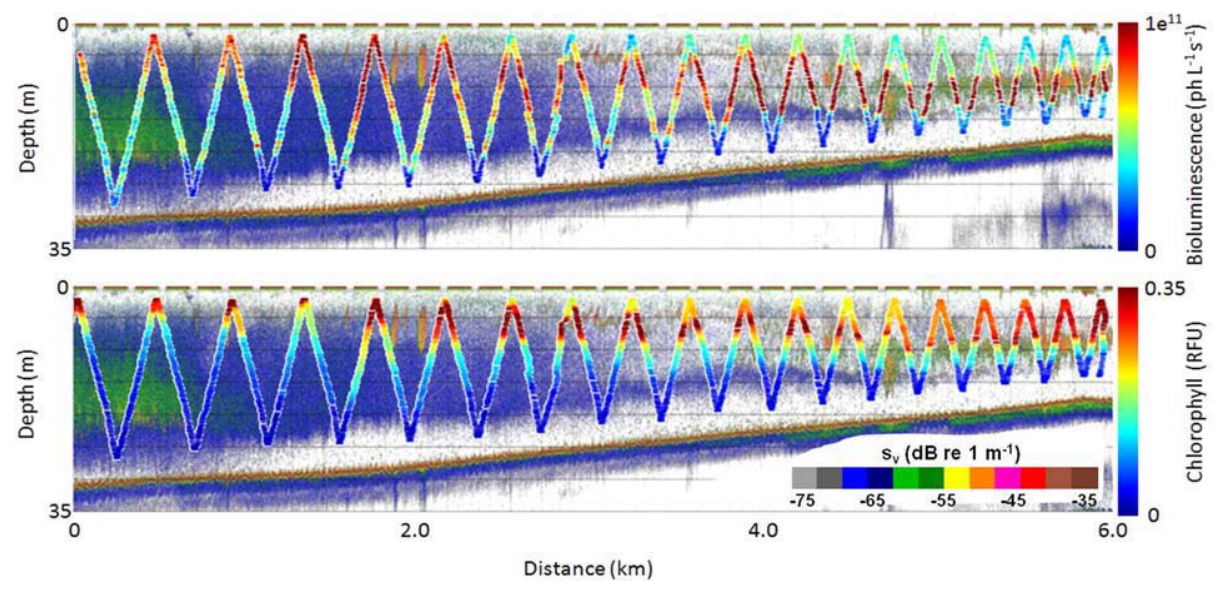

Fig. 2. A transect offshore to onshore taken in Monterey Bay on August 4, 2006. Background for both panels is the $120 \mathrm{kHz}$ acoustic scattering taken from the R/V Shana Rae.

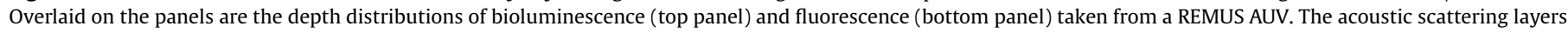
are related to both parameters. High scattering near shore appears to be from bioluminescent zooplankton, indicated by the coefficient of bioluminescence variation,

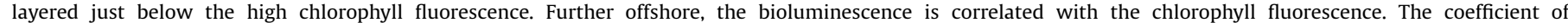

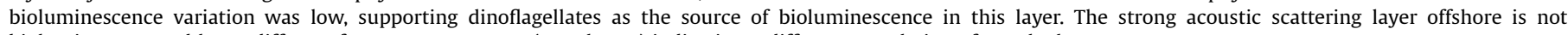
bioluminescent and has a different frequency responses (not shown) indicating a different population of zooplanktons.

hours measured with at least $30 \%$ of profiles from all instruments. Because all layer types from all platforms and instruments were defined using the same method and criteria, it is possible to compare these measures. Across all three studies, zooplankton thin layers were considerably thicker with peaks that were more intense relative to the background and accounted for more of the total water column value than fluorescence thin layers.

Combining information from multiple sensors can provide substantial information on thin plankton layers. For example, Fig. 2 shows acoustic volume scattering taken from the R/V Shana Rae and fluorescence and bioluminescence from the REMUS during the August 2006 study. In this example, high acoustic scattering near shore appears to be from bioluminescent zooplankton, as indicated by values of coefficient of bioluminescence variation. These bioluminescent zooplankton are layered just below the high chlorophyll fluorescence. Further offshore, the bioluminescence is correlated with the chlorophyll fluorescence, showing similar layer shapes and low coefficient of bioluminescence variation values. The strong acoustic scattering layer offshore is not bioluminescent and has a different acoustic frequency response than the inshore layer (not shown), indicating a different population of zooplankton. The relationships between layer types are complex with clear patterns of overlap at some times but not at others. This example shows the complications of interpreting the relationships between layers as well as some of the challenges integrating data from multiple platforms. The remainder of the results will focus on quantifying relationships between thin layers of various types.

\subsubsection{Relationship of bioluminescent layers to other layers}

Of 90 bioluminescent layers in 15 July 2006 data, the peak depth of 10 layers was within $10 \mathrm{~cm}$ of the peak depth of a fluorescent layer in the same REMUS ascent or descent. These 10 bioluminescent layers showed the same shape over depth as the paired fluorescent layer suggesting that these layers were caused by phytoplankton, likely dinoflagellates. Similarly, during the August 2006 sampling, 21 thin bioluminescent layers occurred at the same depth and had the same shape as thin fluorescent layers. During May 2008, 13 bioluminescent layers were at the same depth and had the same profile as thin fluorescent layers. For these 54 bioluminescence layers, the coefficient of bioluminescence variation was less than 0.5 , further supporting the primary source of bioluminescence in these layers as dinoflagellates. In all

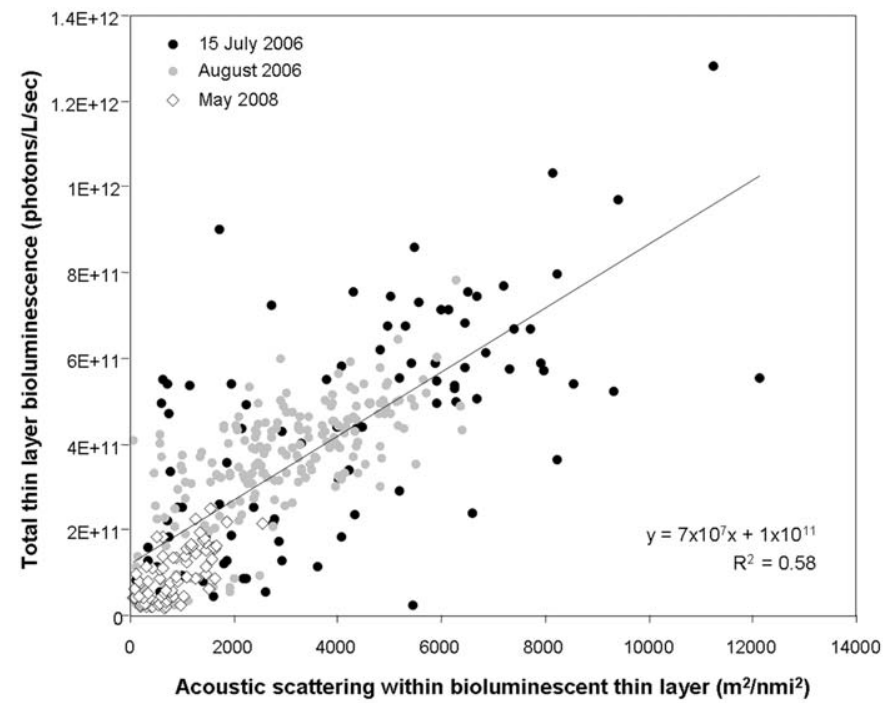

Fig. 3. The integrated bioluminescence over the depth range of each bioluminescent thin layer as a function of the integrated acoustic backscattering over that same depth range is shown for all three studies. Changes in acoustic scattering predict a significant fraction of the variance in layer bioluminescence despite the lack of acoustic thin layers at the many of the locations.

three studies, there was no significant correlation between the fluorescence over the depth range of a bioluminescent thin layer and the integrated bioluminescence within the thin layer $(R<0.05, \quad p>0.05$ for all studies) when all bioluminescent layers were included. However, when only thin bioluminescent layers that occurred at the same depth as fluorescence layers are considered, there was a significant correlation between integrated fluorescence and bioluminescence over the same depth range $(R=0.87 ; p<0.01)$. There was no significant correlation between these 54 bioluminescent layers and acoustic scattering over the same depth interval $(R=0.18 ; p>0.01)$. In this small subset of thin bioluminescent layers, bioluminescent organisms were either co-located strongly with fluorescent species, or more likely autotrophic dinoflagellages were the dominant chlorophyll containing species in the layers.

In the 15 July 2006 data, only 3 bioluminescent layers were clearly associated with an acoustically scattering thin layer with 
equivalent peaks and similar profiles and high coefficient of bioluminescence variation values. In the August 2006 data, 10 thin bioluminescent thin layers matched acoustic thin layers. Finally, in the May 2008 data, 4 thin bioluminescent layers matched thin acoustic layers. The remainder of bioluminescent thin layers in all studies were not clearly associated with thin layers from other measurements. However, in all three studies, after the exclusion of bioluminescent layers that appeared to be caused by phytoplankton (the 54 layers discussed in the previous paragraph), the acoustic scattering strength integrated over the depth of each bioluminescent layer predicted a significant amount of the variance in the integrated bioluminescence within thin layers (Fig. 3; 15 July $2006 R^{2}=0.42$; August $2006 R^{2}=0.47$; May 2008 $R^{2}=0.45$; Total $R^{2}=0.58$; all slopes significantly different from zero $p<0.01)$. This suggests that either the same organisms causing acoustic scattering are also causing bioluminescence or they are strongly co-located. These bioluminescent layers always had a coefficient of variation greater than 0.5 , supporting the conclusion that they are formed by zooplankton. An example of the relationship between bioluminescent thin layers, fluorescent thin layers, and acoustic scattering from one night during the May 2008 study is shown in Fig. 4. A persistent bioluminescent thin layer was detected for about $6 \mathrm{~h}$. Two fluorescent thin layers, one near the surface and one at approximately the depth of the bioluminescent layer appear towards the end of the time series. Prior to about 0100 local time, there were no distinct chlorophyll fluorescence maxima of any thickness. The bioluminescent layer is occasionally correlated with time periods when thin acoustic scattering layers were also present but these layers were typically offset by about $2 \mathrm{~m}$ vertically. Most often, the bioluminescent layer was inside of a relatively thick scattering feature.

\subsubsection{Onshore/offshore effects}

In the 15 July 2005 data, a combination of moored acoustics and REMUS based measurements, the number of phytoplankton and zooplankton layers decreased from K1-K4 (onshore to offshore) while the number of bioluminescence layers increased from K2-K4 (Fig. 5). However, an ANOVA revealed that the site of each mooring had relatively little effect on the characteristics of thin plankton layers (Table 2). These results show that the differences in the probability of detecting layers by mooring site were likely unrelated to changes in the characteristics of the layers that were present. There was a significant effect of time of

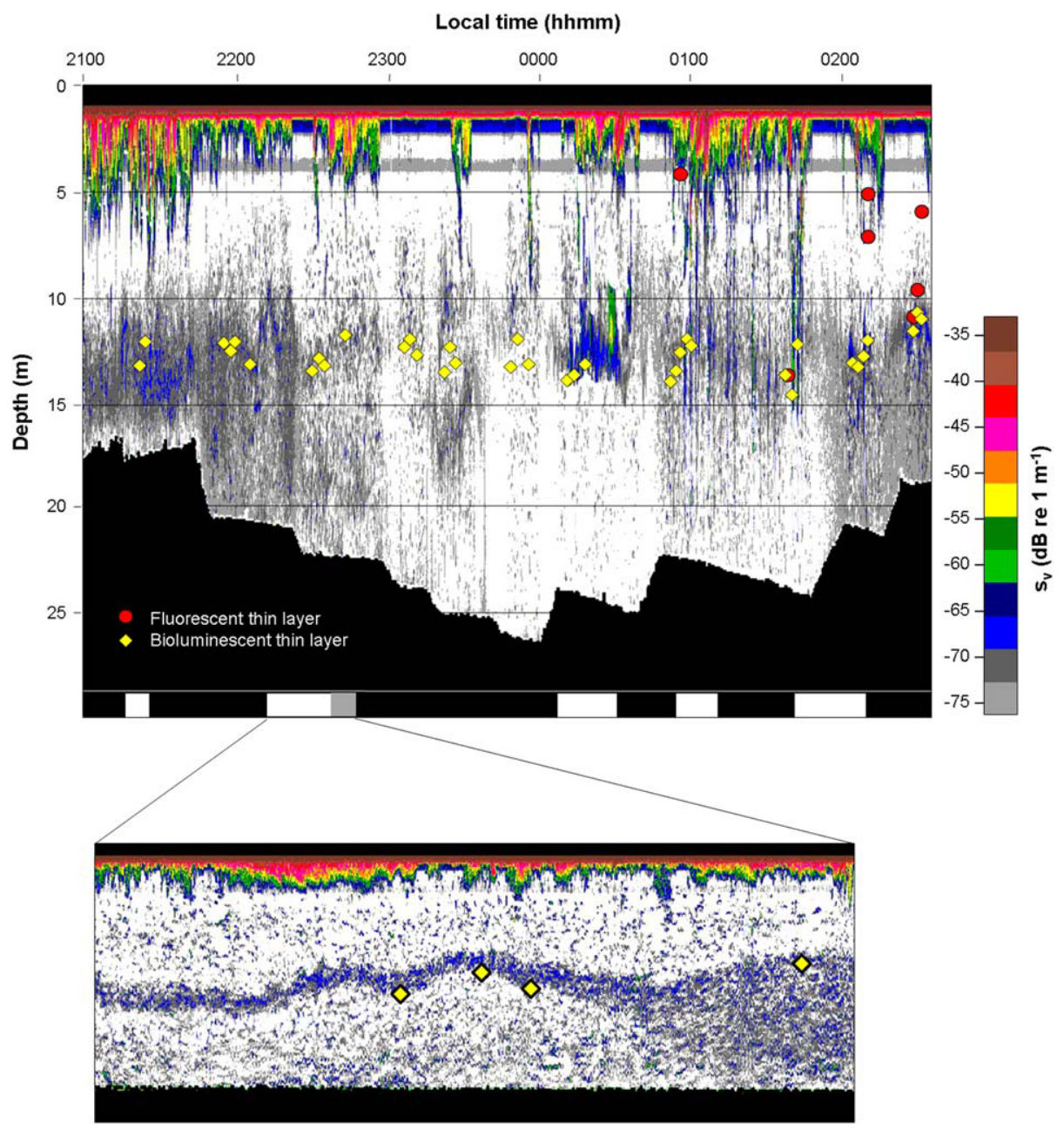

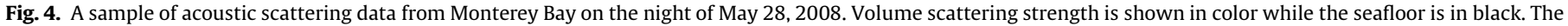

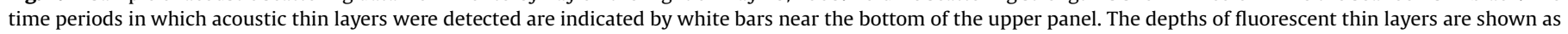

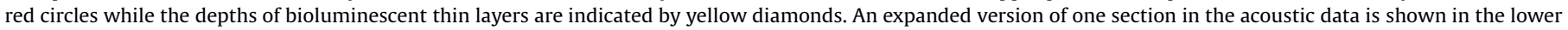

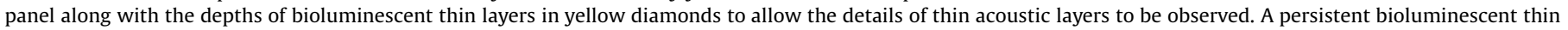

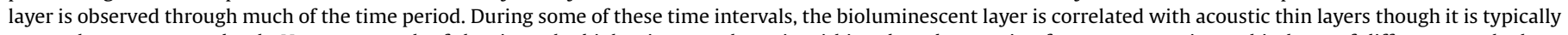

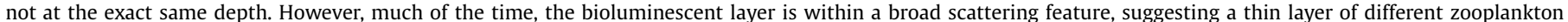
compositions within a broad biomass peak. (For interpretation of the references to colour in this figure legend, the reader is referred to the web version of this article.) 
night on many layer characteristics (Fig. 6). For example, acoustic scattering layers got thinner over the course of the night, by an average of $2.25 \mathrm{~m}$ over $6 \mathrm{~h}$. Bioluminescent layers got thicker, an average of $1.75 \mathrm{~m}$ over $6 \mathrm{~h}$. Optical backscattering layers thickened by about $0.6 \mathrm{~m}$ over $6 \mathrm{~h}$ while fluorescent layers remained unchanged in their thickness over the night. There were also significant interactions of mooring site and time on some layer characteristics, suggesting that these temporal changes varied between mooring sites. This interaction is most evident for the depth of thin layers. For example, at K1 zooplankton layers shallowed over time while at K2 they deepened over the course of the night.

Despite the inability to resolve temporal patterns, data from August 2006 show similar results in onshore-offshore effects. Transects from the REMUS and ship-based measurements were broken up into four sections of increasing distance from the K1 site. Fluorescence layers were found in $89 \%$ of casts in the region closest to the $\mathrm{K} 1$ site, and $81 \%, 59 \%$, and $55 \%$ of casts in the sections successively further from the site, respectively. Optical backscattering layers showed a similar pattern from onshore to offshore abundance with $49 \%$ of the transect closest to K1 containing layers while $48 \%, 46 \%$, and $29 \%$ of profiles in each transect segment successively further from K1 contained layers. The percent of casts containing optically backscattering layers was substantially lower than the percent containing fluorescence layers, despite the fact that fluorescence layers were consistently associated with high optical backscatter. Optical backscattering features were less likely to be defined as thin layers mathema-

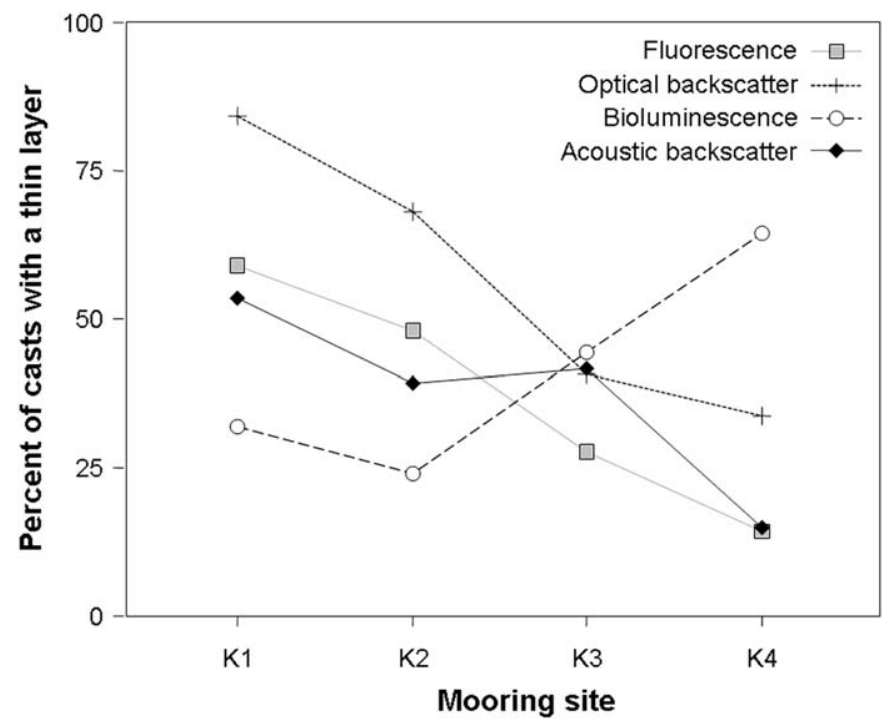

Fig. 5. Percent of total profiles on 15 July 2006 at each mooring site containing thin layers. tically than fluorescence layers because they were not always as sharply defined and often had more variation in background level than fluorescence features, likely because optical backscatter can contain signals from more than living autotrophs, thus giving a broader peak. Acoustic layers were found $56 \%$ of the time in the transect segments closest to $\mathrm{K} 1$, and $51 \%, 40 \%$, and $32 \%$ at each of the three segments increasingly further from K1. Bioluminescence layers showed the opposite pattern with $19 \%$ of casts nearest to K1 containing bioluminescence layers, and 33\%, 53\% and 52\% at sections increasingly further from the $\mathrm{K} 1$ site. As in the 15 July data, ANOVAs revealed that there were no significant effects at the $p=0.05$ level of distance from $\mathrm{K} 1$ categorized in this way on the thickness, depth, or intensity of thin fluorescent, acoustic, or bioluminescent layers.

\subsubsection{Relationship between phytoplankton and zooplankton layers}

Perhaps the most striking onshore-offshore pattern was the difference in the degree of overlap between fluorescent layers of phytoplankton and acoustically scattering layers of zooplankton in the 15 August data. From each half hour increment when layers were present, the closest distance between the peak of a zooplankton layers and the peak of a phytoplankton layer indicated by either fluorescence or optical backscatter was measured in meters. The mean thickness of phytoplankton layers measured by fluorescence was between 0.31 and $0.69 \mathrm{~m}$ with an average base thickness or maximum vertical extent between 0.91 and $2.05 \mathrm{~m}$. The mean thickness of zooplankton layers measured acoustically was between 0.96 and $1.54 \mathrm{~m}$ with a maximum vertical extent between 2.1 and $4.4 \mathrm{~m}$. Given these layer thicknesses, it is likely that zooplankton and phytoplankton layers with peaks within $3 \mathrm{~m}$ of each other are overlapping. A separation of less than $1 \mathrm{~m}$ between layer peaks indicates a high degree of vertical overlap. At $\mathrm{K} 1$, layers were not in $3 \mathrm{~m}$ proximity at any time. At K2, zooplankton and phytoplankton layers were within $3 \mathrm{~m}$ of each other about $1.5 \mathrm{~h}$ during the night but were never within $1 \mathrm{~m}$ of each other. Further offshore, at K3, zooplankton and phytoplankton layers were within $3 \mathrm{~m}$ of each other for $3.5 \mathrm{~h}$ and within $1 \mathrm{~m}$ of each other for $1 \mathrm{~h}$. At the furthest offshore site, layers were only near each other for a total of $2 \mathrm{~h}$ but for that entire period they were less than $1 \mathrm{~m}$ apart. This indicates that zooplankton and phytoplankton layers at $\mathrm{K} 1$ are not interacting directly, while zooplankton and phytoplankton layers at K2 and K3 show increasingly more time spent in close proximity and those at $\mathrm{K} 4$ are highly overlapped in vertical space. This gradient in layer overlap does not correspond with phytoplankton layer thickness or intensity relative to the background, however it corresponds with an increasing proportion of total water column phytoplankton biomass being found in layers from $\mathrm{K} 1$ to $\mathrm{K} 4$. Looking at the relationship in the vertical offset between phytoplankton and zooplankton layers combined across all mooring sites, with an increasing fraction of fluorescence in a

Table 2

Summary of ANOVA results on the effects of mooring site and time on 15 July 2006 thin layer characteristics of peak depth, thickness, intensity relative to local background, and percent of water column integrated value accounted for by the identified layer.

\begin{tabular}{|c|c|c|c|c|c|c|c|c|c|c|c|c|}
\hline & \multicolumn{4}{|c|}{ Mooring site } & \multicolumn{4}{|l|}{ Time } & \multicolumn{4}{|c|}{ Mooring site*Time } \\
\hline & Depth & Thick & Intensity & $\%$ & Depth & Thick & Intensity & $\%$ & Depth & Thick & Intensity & $\%$ \\
\hline Fluorescence layers & & & & $\mathrm{x}$ & $\mathrm{x}$ & & & $\mathrm{x}$ & $\mathrm{x}$ & $\mathrm{x}$ & & $\mathrm{x}$ \\
\hline Optical scattering layers & & & & & $\mathrm{x}$ & $\mathrm{x}$ & $\mathrm{x}$ & & $\mathrm{x}$ & & & \\
\hline Bioluminescent layers & & & & $\mathrm{x}$ & $\mathrm{x}$ & $\mathrm{x}$ & & & & & & \\
\hline Acoustic scattering layers & & & & & & $\mathrm{x}$ & & & $\mathrm{x}$ & & $\mathrm{x}$ & \\
\hline
\end{tabular}

Analyses that were significant at the $p<0.05$ level are indicated by an ' $x$ '. 

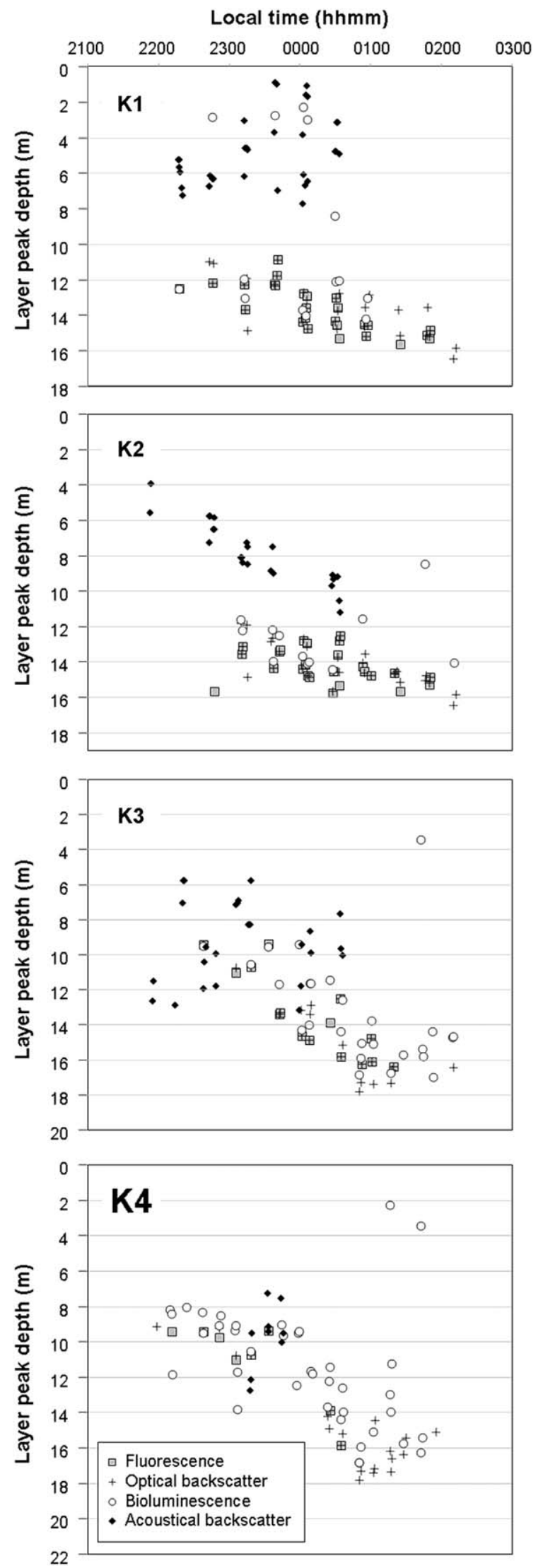

Fig. 6. The depth of the peak of optical and acoustical thin layers at each mooring site over the course of the night of 15 August 2006. Zooplankton and phytoplankton layers showed a gradient in their degree of overlap with no overlap at $\mathrm{K} 1$ and a high degree of overlap at $\mathrm{K} 4$. thin layer relative to the total water there is a decrease in the offset between the phytoplankton layer and the zooplankton layer $\left(R^{2}=0.45, N=47\right)$. Zooplankton layers were found within $3 \mathrm{~m}$ of phytoplankton layers only when the phytoplankton thin layer accounted for more than about $18 \%$ of the total water column integrated chlorophyll. Layer peak fluorescence is correlated with the fraction of total layer fluorescence contained in the phytoplankton layer $\left(R^{2}=0.42, N=47\right)$. There is also a significant relationship between peak fluorescence and the offset between zooplankton and phytoplankton, however it is much weaker $\left(R^{2}=0.22, N=47\right)$.

Both the August 2006 and May 2008 data support the relationship of a decreasing vertical offset between the peaks of zooplankton and phytoplankton layers as the proportion of total chlorophyll in a layer increases. In both of these datasets, the proportion of total fluorescence in a thin layer is only weakly correlated with peak fluorescence (August 2006: $R^{2}=0.12$; May 2008: $R^{2}=0.15$ ). In both studies, the offset between fluorescent and zooplankton layers is significantly predicted by the fraction of total fluorescence in a thin phytoplankton (August 2006: $R^{2}=0.65, N=127$; May 2008: $R^{2}=0.52, N=28$ ) while peak fluorescence was not a significant predictor of the offset (August 2006: $R^{2}=0.06$; May $2008 R^{2}=0.01$ ) nor was the fluorescence peak relative to the local background (August 2006: $R^{2}=0.03$; May 2008: $\left.R^{2}=0.004\right)$. In both of these datasets as well, only when the thin phytoplankton layer accounted for about $20 \%$ of the total water column fluorescence did zooplankton and phytoplankton layers come within $3 \mathrm{~m}$ of each other. Combining all three datasets shows that the fraction of water column fluorescence within a thin layer was a consistent predictor of the vertical offset between the peaks of phytoplankton and zooplankton thin layers in Monterey Bay (Fig. 7, $R^{2}=0.57$ ).

\subsubsection{Physical habitat around layers}

Only during the May 2008 study was sufficient information on the temperature and salinity structure of the water column available for a detailed analysis of the physical habitat. These data were used to test the hypothesis that physical clines could be used by zooplankton as cues for aggregation on phytoplankton. During the 2008 study period, the depth of phytoplankton layers was strongly correlated with the depth of the halocline, thermocline, and pycnocline as indicated by the fraction of the water column's temperature change that occurs within $1 \mathrm{~m}$ of the peak of a fluorescence layer and similarly, the fraction of salinity and density changes that occur around a layer. Given the water column's average depth of $18 \mathrm{~m}$ during the study, if layers were randomly distributed, the average percent of salinity, temperature, or density change in the area $\pm 1 \mathrm{~m}$ of the layer's peak would be less than $10 \%$ of the change over the total water column. However, the percent of total water column change in the area surrounding the layer was $33 \%$ for salinity, $46 \%$ for temperature, and $48 \%$ for density. There was no significant relationship between the strength of the temperature, salinity, density gradient and the fraction of phytoplankton in a layer $(R=0.12$, $p>0.05 ; R=0.28, p>0.05 ; R=0.17, p>0.05$ respectively). There was also no clear association of zooplankton thin layers and strong clines in salinity, temperature, or density.

\section{Discussion}

Previous efforts to examine thin plankton layers have focused on optically scattering and fluorescent features with significantly less emphasis on acoustically scattering features, limited efforts to address bioluminescent layers, and few studies attempting to integrate these various measurements. This work was aimed at 


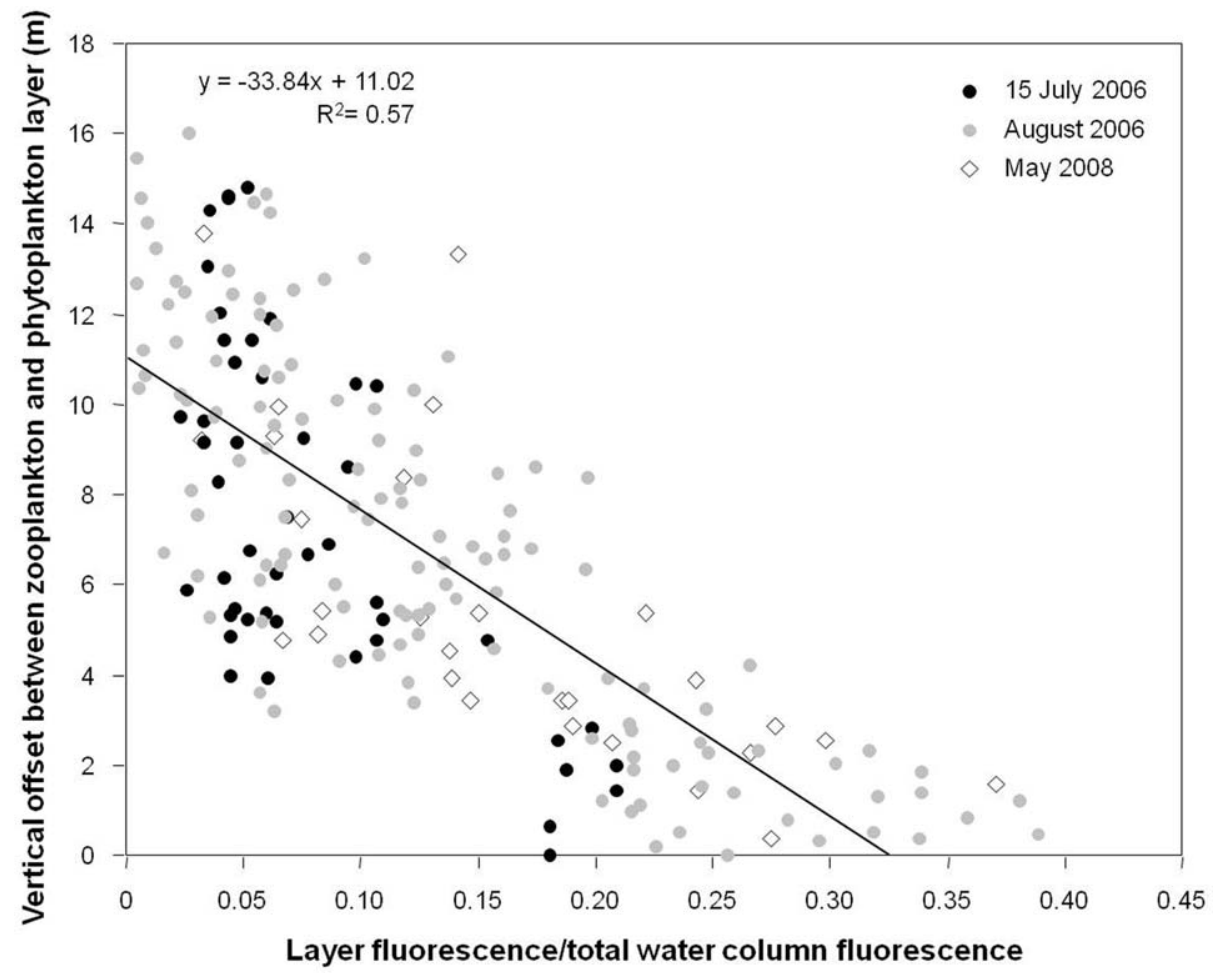

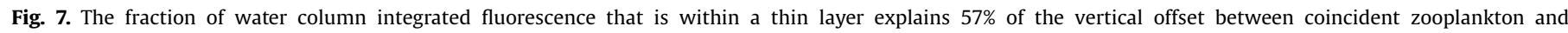
phytoplankton thin layers when all three studies in Monterey Bay were combined. The peak value of the fluorescence and the peak relative to the background were not significant predictors of this offset between layers.

making a step forward in quantifying the associations of layers of a various range of organism sizes and in marrying datasets from the different instruments and platforms used to measure layers of various types. Combining these various measures provided information on the composition of some thin phytoplankton layers. A significant though limited number (between $5 \%$ and $10 \%$ of fluorescent layers in 2006 and 23\% of fluorescent layers in 2008) of bioluminescent thin layers were also fluorescent thin layers. The bioluminescence of these fluorescent layers and their bioluminescence characteristics indicate that they contained significant numbers of dinoflagellates. The presence of dinoflagellate thin layers in the 2006 data is consistent with observations by Sullivan et al. (2009) of the presence but not numerical dominance of thin layers of the toxic dinoflagellate Alexandrium catenella as part of a taxonomically diverse assemblage of phytoplankton.

The combination of optical and acoustical measurements used in this study revealed the presence of cryptic thin layers. Strong thin layers of bioluminescence were identified that were not associated with fluorescent or acoustically scattering thin layers. These layers were not correlated with local fluorescence levels but were correlated with the local acoustic scattering strength despite the absence of an acoustic thin layer. This acoustic scattering was associated with vertically broad peaks or slabs of zooplankton rather than discrete, thin features. This strong correlation between bioluminescence and acoustic scattering indicates that the animals in these bioluminescent layers are similar in their acoustic scattering strength and frequency response to the animals in the vertically broader distribution identified acoustically. This suggests that the thin bioluminescent layers represent features with a distinct zooplankton species composition likely with similar body form (e.g. shape and material properties) to the surrounding vertically broad peak of zooplankton biomass. These compositional thin layers nested inside larger features of biomass may be a common part of the ecosystem (see a similar argument about phytoplankton layers in Rines et al., this issue), however, they are extremely difficult to identify. Most approaches capable of the vertical scales of measurement necessary for the identification of sub-meter scale patterns assess bulk properties, rather than specific composition. However, compositional thin layers are likely to have ecological effects as important as those created by biomass thin layer.

Testing hypotheses regarding zooplankton-phytoplankton associations in situ has been difficult because of problems with sampling resolution (Jaffe et al., 1998). Integrated assessment of thin layers of various organisms provides the ability to examine the relationships between different trophic levels. Previous studies have shown that sometimes layers of various sized plankters are vertically associated but at other times, displaced distributions are observed (Gallager et al., 2004; McManus et al., 2003). Jaffe et al (1998) found no correlation of zooplankton with phytoplankton layers though they saw a correlation with the background fluorescence. Our results similarly showed that optically identified phytoplankton thin layers and acoustically identified zooplankton thin layers were vertically associated at sometimes and not at others. The degree of association was strongly predicted by the percentage of water column chlorophyll within a thin layer with zooplankton layers only found at the depth of phytoplankton thin layers when phytoplankton layers accounted for more than about $20 \%$ of the integrated water column chlorophyll fluorescence. There appeared to be a threshold effect occurring with a steep change in offset between layer peaks when layer fluorescence accounted for less than $17 \%$ of total fluorescence but a relatively flat response in layer offset at values above this. The absolute peak of the fluorescence layer and the layer's fluorescence peak relative to the local background were not significant predictors of the offset between phytoplankton and zooplankton layers. These data suggest that significant trophic 
interactions are occurring between phytoplankton and zooplankton thin layers but phytoplankton thin layers appear to be exploited by zooplankton only when they represent a large fraction of the available phytoplankton. This pattern was consistent between studies in different years and using different combinations of platforms, indicating the importance of this relationship at night within Monterey Bay. The vertical association of zooplankton with phytoplankton only when phytoplankton layers represent a significant portion of water column fluorescence may explain the lack of overlap between phytoplankton and zooplankton by Jaffe et al. where a strong, broad chlorophyll fluorescence maximum made the chlorophyll in identified phytoplankton thin layers a relatively small proportion of the water column integrated chlorophyll (1998). Evidence of ecological interactions (or lack thereof) in thin layers must thus be interpreted in the context of the properties of the entire water column.

The dynamic pattern of vertical association of zooplankton and phytoplankton thin layers observed in Monterey Bay raises questions about how zooplankton identify, cue to, and select phytoplankton thin layers. McManus et al. (2003) suggested the importance of physics in determining the vertical relationships between phytoplankton and zooplankton, while Gallager et al. (2004) emphasized the swimming behavior of zooplankton in response to the physical habitat as a potential cause. Some laboratory studies have shown that zooplankton aggregate at haloclines rather than directly on layers of prey (Bochdansky and Bollens, 2004; Clay et al., 2004). Zooplankton could potentially be cuing to physical clines thin phytoplankton layers were observed to be associated with rather than directly to the phytoplankton layers. However, there was no significant relationship between the strength of the temperature or salinity gradient and the fraction of water column phytoplankton fluorescence within a layer. There was also no clear association of zooplankton thin layers and strong clines in salinity, temperature, or density. While this does not rule out zooplankton finding layers by using these clines, it does suggest that the clines themselves do not lead to the pattern of zooplankton and phytoplankton offset observed as zooplankton must use other information to determine if the layer represents a significant portion of the water column's phytoplankton.

The vertical distribution of zooplankton was related to the fraction of total water column fluorescence rather than the absolute peak of the layer or the peak value relative to a local measure of the background. This suggests that zooplankton have some knowledge of the total water column food availability. Zooplankton may be sampling the entire water column before making decisions on vertical feeding location. In this case, the extensive horizontal extent of these phytoplankton features would be a key in their exploitation by zooplankton grazers as a zooplankter would be able to rely on one profile of the water column to represent an area large relative to its size in making its feeding decisions. Analysis of the horizontal scales of observed phytoplankton thin layers shows that a single vertical excursion by a zooplankter could represent a horizontal area within a phytoplankton layer of about $500 \mathrm{~m}$ despite the fact that phytoplankton layers during both study periods had relatively short horizontal scales compared with thin layers measured during other periods in the same area (for further details, see Moline et al., 2009). Laboratory experiments have shown that some zooplankton can find and exploit phytoplankton thin layers within 30 min (Ignoffo et al., 2005), showing that whatever the mechanism grazers use to detect prey layers, they can be efficient at searching for and cuing to thin layers.

In all phases of this study, zooplankton thin layers were found equally often when phytoplankton were in thin layers and when they were not aggregated into thin layers, when those phyto- plankton layers were a significant portion of the total chlorophyll and when they were not. This indicates that the forces leading to phytoplankton and zooplankton thin layers are likely different and that zooplankton thin layers are formed in response to forces other than simply food. Swimming behavior of zooplankton is clearly an important component driving the vertical distribution of existing thin layers (e.g. Fig. 6) but it is unclear what role swimming plays in the aggregation of zooplankton in the layer itself. Our results provide insight into the processes that affect the depth of zooplankton thin layers, but not their formation and maintenance.

This work was conducted as part of a large, interdisciplinary study, results of which are examined throughout this issue. The LOCO experiment consisted of two scales of study: the process work around the mooring array and larger-scale pattern studies from the ship-based efforts. Our 2006 data provide some insight into the connections between these two studies. Despite differences in measurement platforms, all data show the same pattern: both fluorescent phytoplankton layers and acoustically scattering zooplankton layers became less abundant further offshore of the main mooring array site at K1. However, the thickness, depth, and peak intensity of these layers did not change over the area between $\mathrm{K} 1$ and the innermost extent of the large ship-based study, K4. While layers are less abundant further away from the small-scale study area, layers appear to be coherent across this range and are likely controlled by the same assemblage of physical and biological processes. This has important implications for the comparison of results from the different studies within Monterey Bay during the 2006 LOCO experiment.

\section{Conclusions}

The goal of this work and its companion paper (Moline et al., 2009) was to integrate measurements of thin layers of multiple sizes of organisms in an effort to understand the interactions between adjacent trophic levels, assess the influence of bioluminescence on these interactions, and to elucidate potential mechanisms involved in layer processes. Questions like these cannot be addressed without the integration of measurements taken from multiple platforms, exploiting the strengths of each instrument and measurement approach to provide information at the scales necessary to measure fine-scale structures of plankton. Combined measurements of acoustical scattering, fluorescence, optical backscattering, and bioluminescence revealed cryptic layers of bioluminescent within broader peaks of acoustically scattering zooplankton biomass. Current sampling approaches likely underestimate the true abundance of thin planktonic layers by measuring only bulk properties and not examining compositional layering. However, these compositional thin layers likely have ecological impacts similar to those caused thin layers of total biomass. The combination of measurement approaches used in this study also revealed a pattern in the relationship between the depth of phytoplankton and zooplankton thin layers that was consistent between study periods despite differences in platforms and deployment methodologies. Zooplankton thin layers were found in close proximity in depth to phytoplankton thin layers only when the fluorescence in the thin layer was greater than about $20 \%$ of the total water column integrated fluorescence. Previous studies have found phytoplankton and zooplankton layers overlap in some observations but not in others, something that has been difficult to understand in the context of predatorprey interactions. Our results support the conclusion that phytoplankton thin layers were accessible to zooplankton grazers and that zooplankton did exploit these features. However, zooplankton did so only when food resources were otherwise 
limited. Swimming behavior in response to prey was clearly an important mechanism controlling the depth distribution of zooplankton thin layers but the factors leading to the formation of thin layers must have involved more than prey distribution as thin zooplankton layers occurred both in the presence and absence of phytoplankton thin layers. Our results suggest that zooplankton in thin layers have the ability to sense phytoplankton abundance not only in the vertical vicinity of a thin phytoplankton layer, but over the entire water column. These results highlight the value of integrating measurements of various types of organisms to understand processes in and around thin layers and the importance of assessing ecological interactions in plankton thin layers within the context of the properties of the entire water column, like the animals themselves do.

\section{Acknowledgements}

James Christmann, the captain of the R/V Shana Rae provided exceptional field support. Percy Donaghay, D. Van Holliday, Margaret McManus, and Timothy Cowles facilitated the 2006 field work. Oscar Schofield and Christopher Jones collaborated on the 2008 field work. Ricardo Letelier, WetLabs, and the Pacific Islands Fisheries Science Center loaned equipment for the study. Amanda Ashe set up equipment prior to the 2006 field effort. Daniel Wisdom Jenn Yost, Jessica Connolly, and Chip Haldeman assisted in field operations. Wes Strubhar, Cristina Orrico, and Cyril Johnson at WetLabs provided technical support during 2008 field operations. This work was funded by the Office of Naval Research through Young Investigator Program (Grant\# N0001405-1-0608 to K. Benoit-Bird and Grant\# N00014-03-1-0341 to M. Moline).

\section{References}

Birch, D.A., Young, W.R., Franks, P.J.S., 2008. Thin layers of plankton: formation by shear and death by diffusion. Deep-Sea Research I 55, 277-295.

Blackwell, S.M., Case, J.F., Glenn, S.M., Kohut, J., Moline, M.A., Purcell, M., Schofield, O., von Alt, C., 2002. A new AUV platform for studying near shore bioluminescence structure. In: Kricka, L.J., Stanley, P.E. (Eds.), Bioluminescence and Chemiluminescence Progress and Applications. World Scientific, pp. $197-200$.

Bochdansky, A.B., Bollens, S.M., 2004. Relevant scales in zooplankton ecology: distribution, feeding, and reproduction of the copepod Acartia hudsonica in response to thin layers of the diatom Skeletonema costatum. Limnology and Oceanography 49, 625-636.

Cheriton, O.M., McManus, M.M., Holliday, D.V., Greenlaw, C.F., Donaghay, P.L., Cowles, T.J., 2007. Effects of mesoscale physical processes on thin zooplankton layers at four sites along the west coast of the US. Estuaries and Coasts 30, 575-590.

Clay, T., Bollens, S.M., Bochdansky, A.B., Ignoffo, T.R., 2004. The effects of thin layers on the vertical distribution of larval Pacific herring, Clupea pallasi. Journal of Experimental Marine Biology and Ecology 205, 171-189.

Cowles, T.J., 2003. Planktonic layers: physical and biological interactions on the small scale. In: Seuront, L., Strutton, P. (Eds.), Handbook of Scaling Methods in Aquatic Ecology. CRC Press, Boca Raton, FL, pp. 31-49.

Cowles, T.J., Desiderio, R.A., Carr, M.-E., 1998. Small-scale planktonic structure: persistence and trophic consequences. Oceanography 11, 4-9.

Dekshenieks, M.M., Donaghay, P.L., Sullivan, J.M., Rines, J.E.B., Osborn, T.R., Twardowski, M.S., 2001. Temporal and spatial occurrence of phytoplankton thin layers in relation to physical processes. Marine Ecology Progress Series $223,61-71$.

Donaghay, P.L., Osborn, T.R., 1997. Toward a theory of biological-physical control of harmful algal bloom dynamics and impacts. Limnology and Oceanography 42, 1283-1296.

Donaghay, P.L., Rines, H.M., Sieburth, J.M.N., 1992. Simultaneous sampling of fine scale biological, chemical, and physical structure in stratified waters. Archives of Hydrobiology 36, 97-108.

Foote, K.G., Vestnes, G., Maclennan, D.N., Simmonds, E.J., 1987. Calibration of acoustic instruments for fish density estimation: A practical guide. International Council for the Exploration of the Sea Cooperative Research Report 144, 57 pages.

Gallager, S.M., Yamazaki, H., Davis, C.S., 2004. Contribution of fine-scale vertical structure and swimming behavior to formation of plankton layers on Georges Bank. Marine Ecology Progress Series 276, 27-43.
Herren, C.M., Haddock, S.H.D., Johnson, C.S., Orrico, C.M., Moline, M.A., Case, J.F., 2005. A multi-platform bathyphotometer for fine-scale, coastal bioluminescence research. Limnology and Oceanography: Methods 3, 247-262

Hibler, L.F., Maxwell, A.R., Miller, L.M., Kohn, N.P., Woodruff, D.L., Montes, M.J., Bowles, J.H., Moline, M.A., 2008. Improved fine scale transport model performance using AUV and HSI feedback in a tidally dominated system. Journal of Geophysical Research 113, C08036 doi: 08010.01029/ 02008JC004739.

Holliday, D.V., Donaghay, P.L., Greenlaw, C.F., McGehee, D.E., McManus, M.M., Sullivan, J.M., Miksis, J.L., 2003. Advances in defining fine- and micro-scale pattern in marine plankton. Aquatic Living Resources 16, 131-136.

Holliday, D.V., Pieper, R.E., Greenlaw, C.F., Dawson, J.K., 1998. Acoustical sensing of small scale vertical structures in zooplankton assemblages. Oceanography 11.

Ignoffo, T.R., Bollens, S.M., Bochdansky, A.B., 2005. The effects of thin layers on the vertical distribution of the rotifer, Brachionus plicatilis. Journal of Experimental Marine Biology and Ecology 316, 167-181.

Jaffe, J.S., Franks, P.J.S., Leising, A.W., 1998. Simultaneous imaging of phytoplankton and zooplankton distributions. Oceanography 11, 24-29.

Kang, M., Furusawa, M., Miyashita, K., 2002. Effective and accurate use of difference in mean volume backscattering strength to identify fish and plankton. ICES Journal of Marine Science 59, 794-804.

Klausmeier, C.A., Litchman, E., 2001. Algal games: the vertical distribution of phytoplankton in poorly mixed water columns. Limnology and Oceanography 46, 1998-2007.

Korneliussen, R.J., 2000. Measurement and removal of echo integration noise. ICES Journal of Marine Science 57, 1204-1217.

Lasker, R., 1975. Field criteria for the survival of anchovy larvae: the relation between inshore chlorophyll maximum layers and successful first feeding. Fishery Bulletin 73, 453-462.

Leising, A.W., 2001. Copepod foraging in patchy habitats and thin layers using a 2-D individual-based model. Marine Ecology Progress Series 216, 167-179.

McManus, M.M., Alldredge, A.L., Barnard, A.H., Boss, E., Case, J.F., Cowles, T.J., Donaghay, P.L., Eisner, L.B., Gifford, D.J., Greenlaw, C.F., Herren, C.M., Holliday, D.V., Johnson, D., MacIntyre, S., McGehee, D.E., Osborn, T.R., Perry, M.J., Pieper, R.E., Rines, J.E.B., Smith, C.D., Sullivan, J.M., Talbot, M.K., Twardowski, M.S., Weidemann, A., Zaneveld, J.R., 2003. Characteristics, distribution, and persistence of thin layers over a $48 \mathrm{~h}$ period. Marine Ecology Progress Series 261, 1-19.

McManus, M.M., Cheriton, O.M., Drake, P.J., Holliday, D.V., Storlazzi, C.D., Donaghay, P.L., Greenlaw, C.F., 2005. Effects of physical processes on structure and transport of thin zooplankton layers in the coastal ocean. Marine Ecology Progress Series 301, 199-215.

McManus, M.M., Kudela, R.M., Silver, M.W., Steward, G.F., Donaghay, P.L., Sullivan, D.E., 2007. Cryptic blooms: are thin layers the missing connection?. Estuaries and Coasts 31, 396-401.

Menden-Deuer, S., Grunbaum, D., 2006. Individual foraging behaviors and population distributions of planktonic predator aggregating to phytoplankton thin layers. Limnology and Oceanography 51, 109-116.

Moline, M.A., Blackwell, S.B., Case, J.F., Haddock, S.H.D., Herren, C.M., Orrico, C.M., Terrill, E., 2008. Bioluminescence to reveal structure and interaction of coastal planktonic communities. Deep-Sea Research II 17, 32-43.

Moline, M.A., Blackwell, S.M., Von Alt, C., Allen, B., Austin, T., Case, J.F., Forrester, N. Goldsborough, R., Purcell, M., Stokey, R., 2005. Remote environmental monitoring units: an autonomous vehicle for characterizing coastal environments. Journal of Atmospheric and Oceanic Technology 22, 1797-1808.

Moline, M.A., Heine, E., Case, J.F., Herren, C.M., Schofield, O., 2001. Spatial and temporal variability of bioluminescence potential in coastal regions. In: Case, J.F., Herring, P.J., Haddock, S.H.D., Kricka, L.J., Stanley, P.E. (Eds.), Bioluminescence and Chemiluminescence 2000. World Scientific Publishing Company, Singapore, pp. 123-126.

Moline, M.A., Benoit-Bird, K.J., Robbins, I.C., Schroth-Miller, M., Waluk, C.M., Zelenke, B., 2009. Integrated measurements of acoustical and optical thin layers II: Horizontal length scales. Continental Shelf Research, this issue, doi:10.1016/j.csr.2009.08.004.

Osborn, T.R., 1998. Fine structure, microstructure, and thin layers. Oceanography $11,36-38$.

Rines, J.E.B., Donaghay, P.L., Dekshenieks, M.M., Sullivan, J.M., Twardowski, M.S., 2002. Thin layers and camouflage: hidden Pseudo-nitzschia populations in a fjord in the San Juan Islands, Washington, USA. Marine Ecology Progress Series 225, 123-137.

Ryan, J.P., McManus, M.M., Paduan, J.D., Chavez, F., 2008. Phytoplankton thin layers caused by shear in frontal zones of a coastal upwelling system. Marine Ecology Progress Series 354, 21-34.

Stacey, M.S., McManus, M.M., Steinbuck, J., 2007. Convergences and divergences and thin layer formation and maintenance. Limnology and Oceanography 52 , 1523-1532.

Sullivan, J.M., Twardowski, M.S., Donaghay, P.L., Freeman, S.A., 2005. Use of optical scattering to discriminate particle types in coastal waters. Applied Optics 44, 1667-1680.

Sullivan, J.M., Donaghay, P.L., Rines, J.E.B., 2009. Coastal thin layer dynamics: Consequences to biology and optics. Continental Shelf Research, this issue, doi:10.1016/j.csr.2009.07.009.

Widder, E.A., Johnsen, S., Bernstein, S.A., Case, J.F., Neilson, D.J., 1999. Thin layers of bioluminescent copepods found at density discontinuities in the water column. Marine Biology 134, 429-437. 